\title{
663733 DP-1194
}

AEC RESEARCH AND DEVELOPMENT REPORT

\section{ISOLATION OF ${ }^{147} \mathrm{Pm}$ BY RAPID CATION EXCHANGE CHROMATOGRAPHY}

\section{J.T. LOWE}

SRL RECORD COPY

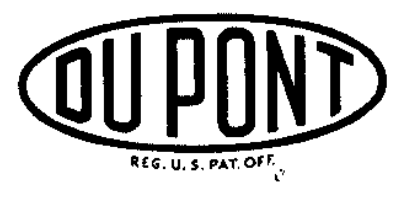

Savannah River Laboratory

Aiken, South Carolina 


\section{LEGAL NOTICE}

This report wae prepared at an account of Gaverament eponoosed work. Nolther the Unilod

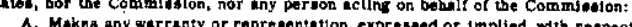

A. Maked any warranty or ropresentation, expreseed or mpled, with reepect to the accuof any taformation, apparatus, mathod, or process diecloeed in this report may that the unte privately owned righte; or

g. Aosumes eny lieblitisen with reopect to the une of, or for damages reouiting from the use of any information, apparatue. method, or procese disclosed in thas report.

$A$ used in the sbove. "peraon acting on behalf of the Commination" Includes any em. ployee or contractor of the Commisvion, or employee of such confractor, to the extent that uncb employee or contractor of the Commisalon, or employee of such contractor prepares. disserinates, or provides acces! to, any informatlon pursuant to ha employment or contraci wtth the commisetion, or hit employment with such contractor.

Printed in the United States of America Available from

Clearinghouse for Federal Scientific and Technical Information National Bureau of Standards, U. S. Department of Commerce Springfield, Virginia 22151

Price: Printed Copy $\$ 3.00$; Microfiche $\$ 0.65$ 


\section{ISOLATION OF ${ }^{147} \mathrm{Pm}$ BY RAPID CATION EXCHANGE CHROMATOGRAPHY}

by

J. T. Lowe

Approved by

E. L. Albenesius, Research Manager Separations Chemistry Division

Ju1y 1969

E. I. DU PONT DE NEMOURS \& COMPANY SAVANNAH RIVER LABORATORY

AIKEN, S. C. 29801

CONTRACT AT(07.2).1 WITH THE

UNITED STATES ATOMIC ENERGY COMMISSION 
ABSTRACT

A rapid cation exchange process was developed to separate ${ }^{147} \mathrm{Pm}$ from other fission product 1 anthanides by displacement development chromatography. Flow rates four times those used in conventional gravity-fed systems were achieved in pressurized columns containing sma11 particle resin.

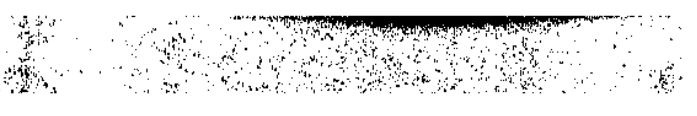


LIST OF TABLES AND FIGURES . . . . . . . . . . . . . . . . 4

INTRODUCTION . . . . . . . . . . . . . . . . 5

SUMMARY . . . . . . . . . . . . . . . . . . 6

DISCUSSION . . . . . . . . . . . . . . . . 6

Process Description. . . . . . . . . . . . . 6

Ion Exchange Process . . . . . . . . . . . 6

Calculation of Process Performance. . . . . . . 8

Advantages of Pressurized Columns . . . . . . . . 11

Scouting Tests with Nonradioactive Lanthanides . . . 11

Equipment and Procedures . . . . . . . . . . . 12

Results . . . . . . . . . . . . . . . 14

${ }^{147} \mathrm{Pm}$ Separation Test... . . . . . . . . . . 16

Equipment .................. 19

Results ................. . 21

ACKNOWLEDGMENT . . . . . . . . . . . . . . . . . 22

APPENDIX A. Calculation of Minimum Movement Distance 23

APPENDIX B. Feed Preparation for ${ }^{147} \mathrm{Pm}$ Separations

Test................ . 24

APPENDIX C. Safety Analysis of Four-Column System . . . . 27

REFERENCES . . . . . . . . . . . . . . . . . 29 


\section{LIST OF TABLES AND FIGURES}

$\underline{\text { Page }}$

Table

I Promethium Separation Factors . . . . . . . . . . 12

II Relative Amounts of ${ }^{147} \mathrm{Pm}$ in Eluate Fractions . . . 21

II Results of ${ }^{147} \mathrm{Pm}$ Separation by Ion Exchange . . . . . 22

\section{$\underline{\text { Figure }}$}

1 Simplified Representation of Sequential Reactions

in Displacement Development . . . . . . . . . . . 7

2 Four-Column System Used in ${ }^{147} \mathrm{Pm}$ Separation Test . . 13

3 Typical Separation Curve in Displacement Development Tests.................... 15

4 Variation of Theoretical Plate Height with Temperature (DTPA) . . . . . . . . . . . . 17

$\dot{S}$ Variation of Theoretical plate Height with Flow Rate (DTPA and NTA) . . . . . . . . . . 18

6 Photograph of Four-Column System . . . . . . . 20 
Promethium-147 has several properties that make it attractive as a possible isotopic power source. Its 2.7 year half-1ife is long enough for many terrestrial and space applications; it was initially considered a candidate power source for an artificial heart(1) although subsequent development of exacting shielding and service cycle specifications now 1 imit its potential in this application. ${ }^{147} \mathrm{Pm}$ decays to $\mathrm{stable}{ }^{147} \mathrm{Sm}$ by beta emission only; the maximum bremsstrahlung energy is $0.025 \mathrm{Mev}$. Radioisotopic contaminants are ${ }^{146} \mathrm{Pm}\left(t_{\frac{1}{2}}=4.4\right.$ years $)$ and ${ }^{148} \mathrm{Pm}\left(t_{\frac{1}{2}}=42\right.$ days $)$; both of these isotopes emit penetrating gamma radiation in high abundance. At reactor discharge, the composition of fission product promethium is $\sim 0.2 \mathrm{ppm}{ }^{146} \mathrm{Pm}$ and $\sim 5 \%{ }^{148} \mathrm{Pm}$; the ${ }^{148} \mathrm{Pm}$ but not the ${ }^{146} \mathrm{Pm}$ can be reduced to an insignificant radiation level by $\sim 2.5$ years of decay.

$2{ }^{47} \mathrm{Pm}\left(2.6 \%\right.$ fission yield from $\left.{ }^{235} \mathrm{U}\right)$ is present in wastes from Savannah River Plant (SRP) separations processes and can be recovered with other lanthanide fission products from highly salted wastes $\left(\sim 2 \mathrm{M} \mathrm{Al}\left(\mathrm{NO}_{3}\right)_{3} \text { or } 6 \mathrm{M} \mathrm{NaNO}\right)_{3}$ by batch extraction with $50 \%$ tributyl phosphate (TBP).

Both solvent extraction(2) and chromatographic cation exchange (3-5) processes have been proposed for isolation of individual elements from lanthanide mixtures. Cation exchange chromatography is preferred for lanthanide, separations, and has been used to purify several hundred grams of ${ }^{147} \mathrm{Pm}$. (4) Solvent extraction has not been demonstrated successfully on a multigram scale.

This report describes a rapid cation exchange process developed at the Savannah River Laboratory (SRL) to separate ${ }^{1{ }^{4}} \mathrm{Pm}$ from other fission product lanthanides. Small particle (30- to 60-micron) cation exchange resins are used in pressurized columns. The process utilizes displacement development and is applicable to large-scale separations. Previous large-scale chromatographic separation methods have used conventional 100 - to $200-m i c r o n$ resins and gravity flows. Small particle cation resin has been used at Oak Ridge National Laboratory (ORNL) for separation of milligram quantities of lanthanides by elution development. (6) 
Rapid cation exchange chromatography was shown to be an improved process for purification of ${ }^{147} \mathrm{Pm}$. One gram of ${ }^{147} \mathrm{Pm}$ was separated from a 30 -gram mixture of fission product 1 anthanides in a laboratory test; no lanthanide activity, other than promethium isotopes, could be detected in the product solution. High flow rates were achieved by using small particle $(30-60 \mu)$ cation exchange resin, "Dowex"* 50W-X8; pressures up to 800 psig were used to force developing reagent solution through the columns at $15 \mathrm{ml} /(\mathrm{min})\left(\mathrm{cm}^{2}\right)$, approximately four times the rate used in conventional gravity-fed columns.

\section{DISCUSSION}

\section{Process Description}

Ion Exchange Process

Because cation resin shows little selectivity among lanthanides, a chelating agent must be used to separate the lanthanides into separate bands. Two types of chromatographic development are applicable to lanthanide separations, elution development and displacement development. (7) Displacement development was selected because elution development is applicable only to smal1scale ( $<1 \mathrm{~g}$ ) separations; a smaller fraction of the column can be loaded, and band velocities are only $210 \%$ of the band velocities in displacement development.

A simplified representation of displacement development is shown in Figure 1 .

- The column is initially loaded with a cation (A) that has less affinity for the resin than the ions to be separated.

- A mixture of the ions to be separated ( $B$ and $C$ ) is loaded onto the column. Because $B$ and $C$ are more strongly sorbed, they displace A cations from the column. As mentioned previously, lanthanides are not separated during loading.

*Trademark of Dow Chemical Company 


\begin{tabular}{|c|c|c|c|c|}
\hline $\mid \begin{array}{l}\mathbf{A} \\
\mathbf{A} \\
\mathbf{A} \\
\mathbf{A}\end{array}$ & $\left|\begin{array}{l}C \\
B \\
C \\
B\end{array}\right|$ & $\left|\begin{array}{l}D \\
D \\
D \\
D\end{array}\right|$ & $\mid \begin{array}{l}\mathbf{D} \\
\mathrm{D} \\
\mathbf{D} \\
\mathbf{D}\end{array}$ & $\left|\begin{array}{l}D \\
D \\
D \\
D\end{array}\right|$ \\
\hline $\begin{array}{l}\text { AAA } \\
\text { AAA } \\
\text { AAA } \\
\text { AAA } \\
\text { AAA } \\
\text { AAA } \\
\text { AAA } \\
\text { AAA } \\
\text { AAA } \\
\text { AAA } \\
\text { AAA } \\
\text { AAA } \\
\text { AAA } \\
\text { AAA } \\
\text { AAA } \\
\text { AAA } \\
\text { AAA } \\
\text { AAA } \\
\text { AAA }\end{array}$ & $\begin{array}{l}\text { CCB } \\
\text { BCC } \\
\text { CBC } \\
\text { CCB } \\
\text { BCC } \\
\text { CBC } \\
\text { CCB } \\
\text { BCC } \\
\text { AAA } \\
\text { AAA } \\
\text { AAA } \\
\text { AAA } \\
\text { AAA } \\
\text { AAA } \\
\text { AAA } \\
\text { AAA } \\
\text { AAA } \\
\text { AAA } \\
\text { AAA }\end{array}$ & $\begin{array}{l}\text { DDD } \\
\text { DDD } \\
\text { DDD } \\
\text { DDD } \\
\text { DDD } \\
\text { DDD } \\
\text { DDD } \\
\text { DDD } \\
\text { DDD } \\
\text { DDD } \\
C C C \\
C C C \\
C C C \\
C C C \\
\text { BBB } \\
\text { BBB } \\
\text { BBB } \\
\text { BBB } \\
\text { AAA }\end{array}$ & $\begin{array}{l}\text { DDD } \\
\text { DDD } \\
\text { DDD } \\
\text { DDD } \\
\text { DDD } \\
\text { DDD } \\
\text { DDD } \\
\text { DDD } \\
\text { DDD } \\
\text { DDD } \\
\text { DDD } \\
\text { DDD } \\
C C C \\
C C C \\
C C C \\
C C C \\
\text { BBB } \\
\text { BBB } \\
\text { BBB }\end{array}$ & $\begin{array}{l}\text { DDD } \\
\text { DDD } \\
D D D \\
D D D \\
D D D \\
D D D \\
D D D \\
D D D \\
D D D \\
D D D \\
D D D \\
D D D \\
D D D \\
D D D \\
D D D \\
D D D \\
C C C \\
C C C \\
C C C \\
\end{array}$ \\
\hline$\left|\begin{array}{l}\mathbf{A} \\
\mathbf{A} \\
\mathbf{A}\end{array}\right|$ & $\left|\begin{array}{l}\mathbf{A} \\
\mathbf{A} \\
\mathbf{A}\end{array}\right|$ & $\begin{array}{l}\mathbf{A} \\
\mathbf{A} \\
\mathbf{A}\end{array}$ & $\mid \begin{array}{l}\mathbf{B} \\
\mathbf{B} \\
\mathbf{B}\end{array}$ & $\left|\begin{array}{l}c \\
c \\
c\end{array}\right|$ \\
\hline
\end{tabular}

FIG. 1 SIMPLIFIED REPRESENTATION OF SEQUENTIAL REACTIONS IN DISPLACEMENT DEVELOPMENT 
- A solution containing a salt of cation (D) and a chelating agent is next passed through the column.

- On continued passage of complexant solution through the column, a band of pure $B$ moves ahead of $a$ band of pure $C$, and both bands move at the same rate down the column. Fractions containing pure $B$ and pure $C$ are collected as they leave the column.

The chelating agent must meet several requirements:

- It must have less affinity for cation $D$ than for either $B$ or $C$, to prevent the trailing lanthanide band from spreading as displacement progresses.

- It must sufficiently discriminate between the individual lanthanides $B$ and $C$ to separate them into distinct bands.

- It must have greater affinity for cation $A$ than for $B$ and $C$ in order to maintain the leading lanthanide band as sharp as possible, i.e., to prevent spreading of lanthanides throughout the column.

Although the actual displacement process is somewhat more complicated, extension to a description sufficiently accurate for calculation of process performance is not difficult. The preceding treatment does not account for failure of reactions to reach equilibrium at each point in the column. Although a direct calculation of the kinetics is not possible except for the simplest models, all nonequilibrium conditions can be empirically included in one experimentally determined parameter, the theoretical plate height. Calculation of process performance is presented in the following section.

\section{Calculation of Process Performance}

To describe mathematically the calculation of displacement cation exchange chromatography, it is first necessary to define several terms. The separation factor $\alpha_{C}^{B}$ for two cations $B$ and $C$ is defined as the ratio of the concentration of $B$ in solution to its concentration in the resin phase, divided by the same ratio for component $C$, 


$$
\alpha_{C}^{B}=\frac{[B] /[\bar{B}]}{[C] /[\bar{C}]}=\frac{[B][\bar{C}]}{[\bar{B}][C]},
$$

where the barred and unbarred symbols designate resin and solution concentrations, respectively.

For chelating agents that form very strong, negatively charged $1: 1$ complexes with the lanthanides, the separation factor reduces to ${ }^{(8)}$

$$
\alpha_{C}^{B}=\frac{K_{B C h}}{K_{C C h}},
$$

where $K_{B C h}$ and $K_{C C h}$ are the respective stability constants of the chelating agents with cations $B$ and $C$.

As mentioned in the preceding qualitative description, bands of pure $B$ and $C$ develop after the mixture has been displaced some distance. The minimum number, $\gamma$, of band lengths of displacement required to attain steady state boundaries is given by ${ }^{(8)}$

$$
\gamma_{B, C}=\frac{1+\left(\alpha_{C}^{B}-1\right) N_{o}}{\left(\alpha_{C}^{B}-1\right)}
$$

where $\mathrm{N}_{0}$ is the mole fraction of component $\mathrm{B}$ in the mixture. For multicomponent mixtures a conservative estimate can be made by applying Equation 3 with $B$ and $C$ representing the two cations having the smallest separation factor, and $N_{0}$ replaced by the mole fraction of all components having stability constants smaller in magnitude than that of $B{ }^{(7)}$ An example of the calculations is given in Appendix A.

Failure to achieve equilibrium at each point can be accounted for by introduction of a single experimentally determined parameter, the theoretical plate height. It is defined by the equation $(8)$ 


$$
\begin{aligned}
& \log \frac{([\bar{B}] /[\bar{C}])_{1}}{([\bar{B}] /[\bar{C}])_{2}}=\frac{L}{h} \log \alpha_{C}^{B}, \text { where } \\
&([\vec{B}] /[\bar{C}])_{i}= \text { ratio of the concentrations of } B \text { and } C \text { in } \\
& \text { the resin at point i in the overlap region, } \\
& i=1,2 \\
& L= \text { distance between points } 1 \text { and } 2, \mathrm{~cm} \\
& h= \text { theoretical plate height, cm } \\
& \alpha_{C}^{B}= \text { separation factor for cations } B \text { and } C
\end{aligned}
$$

The rate at which equilibrium is approached and, therefore, the magnitude of the theoretical plate height, depends on several experimental variables: temperature, flow rate, and resin particle size.

The theoretical plate height is lowered by operation at elevated temperature, which increases the rate of diffusion. Similarly, lowering the flow rate permits more time for equilibrium to be established at each point, decreasing the theoretical plate height. Decreasing resin particle size decreases the boundary layer film thickness through which the cations must diffuse, thus decreasing theoretical plate height. The theoretical plate height, and, therefore, the length of the binary zone, is approximately independent of column diameter, but the total band length is increased by reducing the column diameter. Thus, a larger fraction can be recovered pure by reducing the column diameter.

Each of these variables has a limited practical range, however. As the temperature is increased, column gassing increases, and the rates of side reactions, such as decomposition of chelating agent, may also increase. Lowering the flow rate not only increases processing time, but a1so increases radiolytic degradation of the resin. Similarly, in decreasing the column diameter, the flow rate must be reduced to maintain a constant rate of band advance. Decreasing resin particle size is limited only by the pressure drop that is acceptable for process equipment. 


\section{Advantages of Pressurized columns}

Several advantages result from use of small particle cation exchange resin in pressurized columns. Diffusion distances are decreased, both in the resin particle and in the aqueous film surrounding the particle. One of two potential improvements in a separation process will result from use of smaller resin particles. If the flow rate is held constant, decreasing resin particle size will decrease the length of the overlap region: i.e., lower the theoretical plate height. Alternatively, if the length of the overlap zone is held constant, the flow rate can be increased as resin particle size is decreased. The quality of separation achieved by Wheelwright $(4,5)$ is adequate for promethium recovery; so the object of this work was to increase the flow rate and maintain the quality of separation. The only operating variables that required re-evaluation from wheelwright's study in gravity-fed columns were flow rate and operating temperatures, because optimum concentration and $\mathrm{pH}$ of eluting agent, and the relative performance of a series of chelating agents should be independent of resin particle size.

\section{Scouting Tests with Nonradioactive Lanthanides}

Studies by Wheelwright $(4,5,9)$ indicate that the two chelating agents most effective for separation of fission product lanthanides are diethylenetriaminepentaacetic acid (DTPA) and nitrilotriacetic acid (NTA). Separation factors for promethium and several other fission product lanthanides are shown in Table I. The values in Table I are probably accurate to \pm 0.5 , based on the uncertainty in both the reported data and in the unknown promethium stability constants which are taken to be the averages of the stability constants for samarium and neodymium. 
TABLE I

Promethium Separation Factors

\section{Rare Earth Pair}

$\mathrm{Pm}-\mathrm{La}$

$\mathrm{Pm}-\mathrm{Ce}$

$\mathrm{Pm}-\mathrm{Pr}$

$\mathrm{Pm}-\mathrm{Nd}$

$\mathrm{Sm}-\mathrm{Pm}$

$\mathrm{Eu}-\mathrm{Pm}$

$\mathrm{Y}-\mathrm{Pm}$

\begin{tabular}{|c|c|}
\hline \multicolumn{2}{|c|}{ Separation Factors (a) } \\
\hline NTA & DTPA \\
\hline 10.1 & 310 \\
\hline 3.7 & 29.5 \\
\hline 2.1 & 8.0 \\
\hline 1.4 & 2.3 \\
\hline 1.3 & 2.3 \\
\hline 1.3 & 2.3 \\
\hline 1.2 & 1.2 \\
\hline
\end{tabular}

(a) Temperature: $25^{\circ} \mathrm{C}$

The $\mathrm{pH}$ of the chelating agent solution fixes the concentration of the free chelating anion. At low $\mathrm{pH}$ (less than $\sim 4$ ), there is a low concentration of free chelating anion, which leads to elution development. At very high $\mathrm{pH}$, the equilibrium between resin and complexing agent is too favorable toward the complexing agent, which prevents the lanthanides from being sufficiently sorbed by the resin to achieve separation. Displacement development is obtained between $\mathrm{pH}$ 5-7 for DTPA, and between $\mathrm{pH} \mathrm{6-7}$ for NTA.

\section{Equipment and Procedures}

The experimental system used in the scouting tests is shown schematically in Figure 2. A Milton Roy Company positive displacement pump (Model 80993), designed to operate at pressures up to 1300 psig, was used to pump solution through the column. The resin was retained at the bottom of the column by a G-porosity (10 micron) stainless steel frit. The column was enclosed in a heating jacket, through which water controlled to $\pm 1.0^{\circ} \mathrm{C}$ was circulated from an adjacent water bath. The column was a 5-foot length of $1 / 2$-inch-ID stainless steel tubing with 0.035 -inchthick wall. The allowable working pressure was 2780 psi, based 


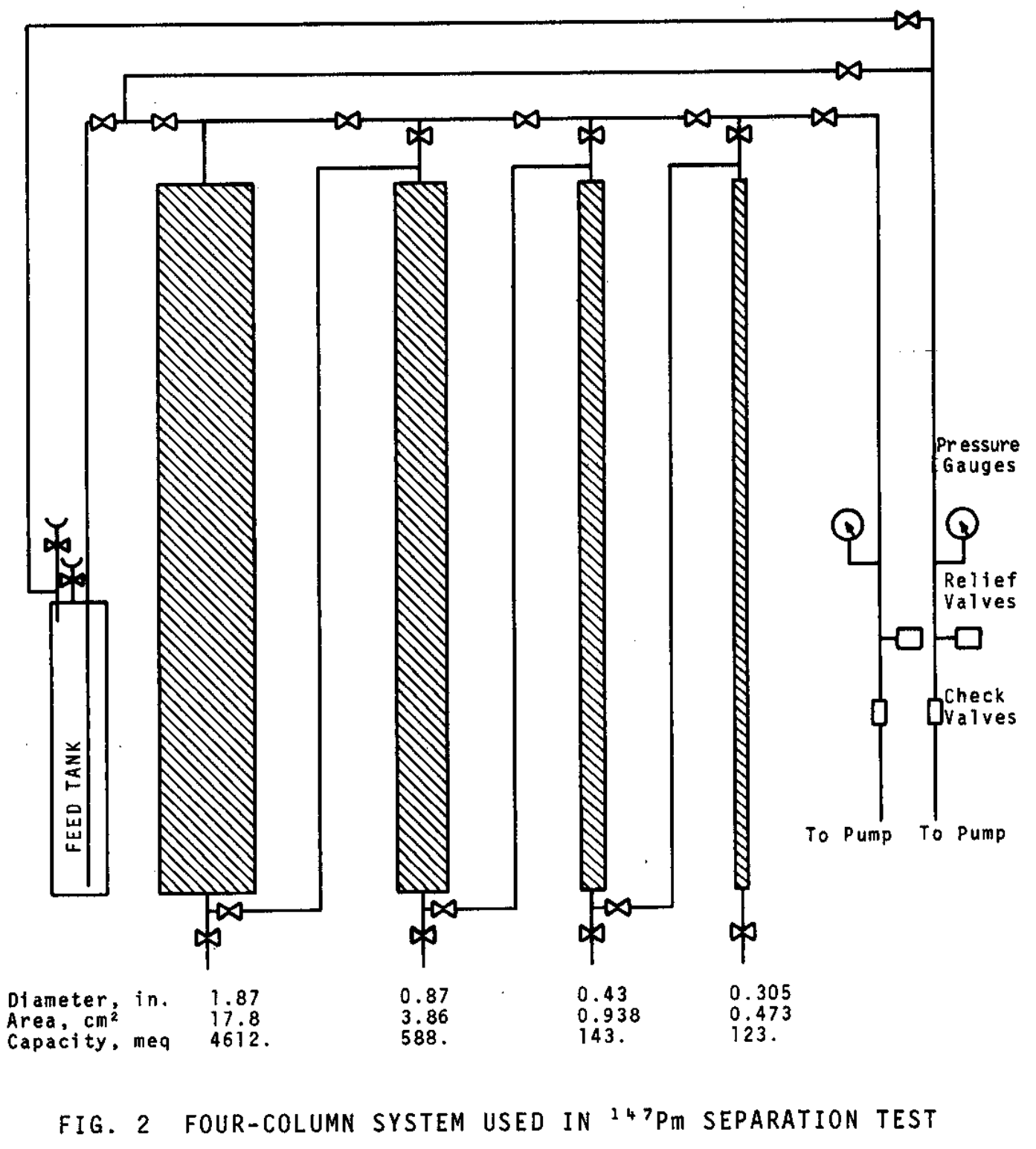


on design calculations from the ASME Unfired Pressure Vesse1 Code. The relief valve, set at 1000 psig, was installed between the pump and first valve to eliminate the possibility of pressures greater than 1000 psi anywhere in the system.

Equimolar mixtures of samarium, neodymium, and praseodymium were separated in tests with nonradioactive solutions to determine theoretical plate heights over a range of operating conditions. The barrier ion, cation $\mathrm{A}$, was $\mathrm{Zn}^{2+}$ in all tests. A typical column effluent profile from the preliminary experiments is shown in Figure 3. The three pure bands are separated by two overlap regions, representing a $\mathrm{Sm}-\mathrm{Nd}$ mixture and a $\mathrm{Nd}-\mathrm{Pr}$ mixture.

Several samples were taken of the effluent in both overlap regions for each test run. The concentration of each component was determined with a Beckman Instruments, Incorporated, Model DB spectrophotometer using the samarium peak at $402 \mathrm{m \mu}$, the praseodymium peak at $470 \mathrm{m \mu}$, and the neodymium peak at $581 \mathrm{m \mu}$. (10) Sample cells $(4-\mathrm{cm})$ permitted determination of concentrations of samarium as $10 \mathrm{w}$ as $0.003 \mathrm{M}$, and neodymium and praseodymium as $10 \mathrm{w}$ as $0.001 \mathrm{M}$, although extinction coefficients are less than $10 \mathrm{l} /(\mathrm{mole})(\mathrm{cm})$ for each of the peaks. For each sample in the $\mathrm{Sm}-\mathrm{Nd}$ or $\mathrm{Nd}-\mathrm{Pr}$ binary zones the theoretical plate height was calculated from Equation 4. A least squares fit of the several values in each zone, together with the standard deviation, was calculated with an IBM $360 / 65$ computer, using the experimental concentrations as input data.

\section{Results}

After a few experiments established that the steady state band shape is achieved when the band has moved a distance of two band lengths with either DTPA or NTA, the top third of the column was loaded and the band displaced two band lengths in subsequent tests. The effect of both temperature and flow rate on the theoretical plate height was determined. 


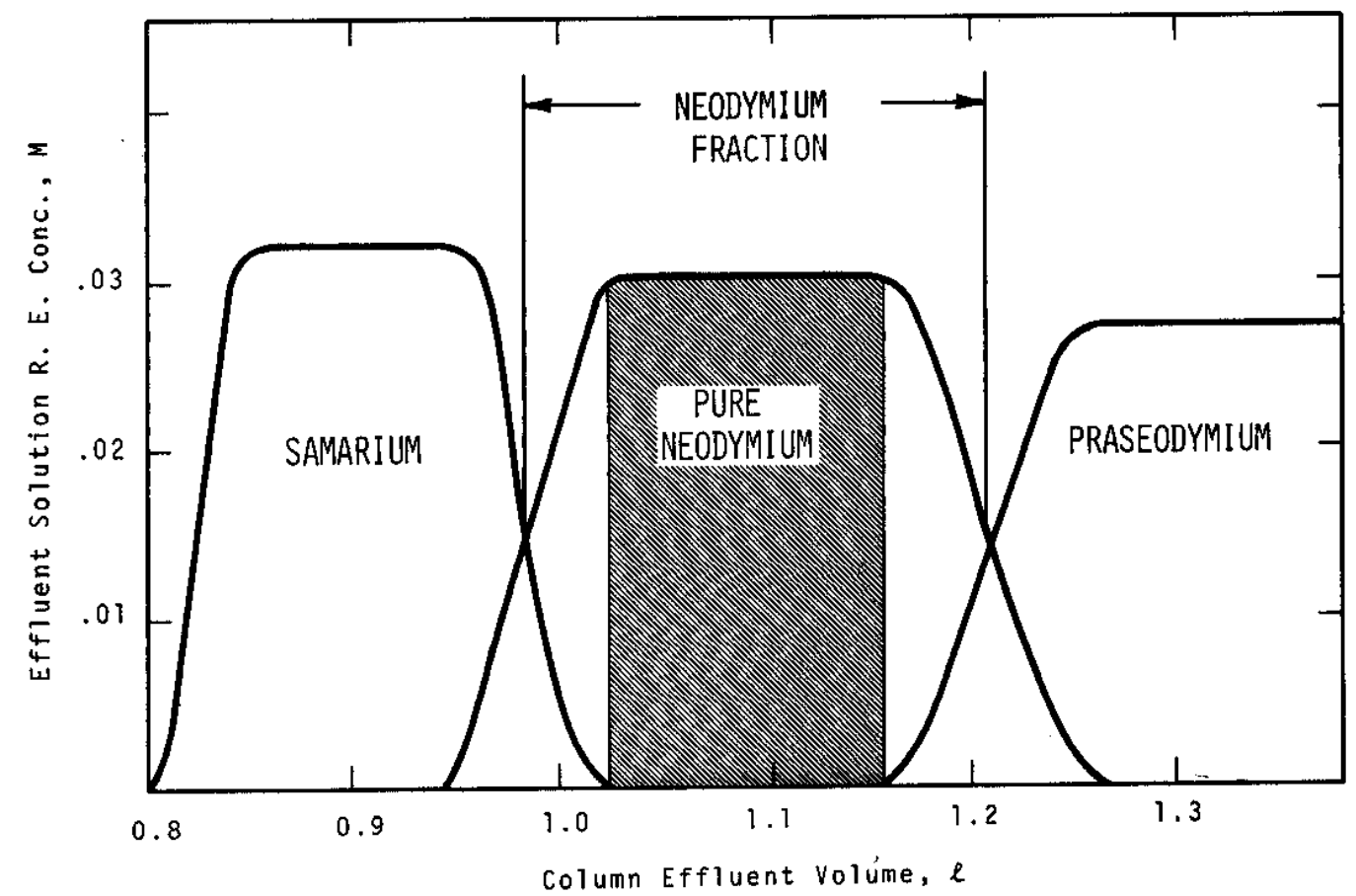

FIG. 3 TYPICAL SEPARATION CURVE IN DISPLACEMENT DEVELOPMENT TESTS Example of separation with $0.05 \mathrm{M}$ DTPA, pH 6.0 at $70^{\circ} \mathrm{C}$. The slope of the overlap region iines determine the quality of the separation. 
A series of experiments determined the influence of operating temperature on the theoretical plate height, with DTPA as the chelating agent. A flow rate of $13.5 \mathrm{~m} 1 /(\mathrm{min})\left(\mathrm{cm}^{2}\right)$ was used in each of these tests. The results are plotted in Figure 4 for 50 to $80^{\circ} \mathrm{C}$. One run at $25^{\circ} \mathrm{C}$ gave very poor separation, with an estimated theoretical plate height of $\sim 5 \mathrm{~cm}$. Little decrease in theoretical plate height was achieved by increasing the temperature over $70^{\circ} \mathrm{C}$.

The effect of flow rate on theoretical plate height was tested from 10.8 to $19.0 \mathrm{ml} /(\mathrm{min})\left(\mathrm{cm}^{2}\right)$ with DTPA and NTA at $70^{\circ} \mathrm{C}$. The results are shown in Figure 5. Although the theoretical plate heights are smaller with NTA, above a flow rate of $12 \mathrm{ml} /(\mathrm{min})\left(\mathrm{cm}^{2}\right)$, the separation factors for NTA are also smaller, as shown in Table I. Since the overlap region depends on both parameters (Equation 4), the quality of separation in the nonradioactive tests was approximately equal with NTA and DTPA.

The conditions that are chosen for a separation depend on the separation factor for the components to be separated. For example, a much higher flow rate can be used for a $\mathrm{Pm}-\mathrm{Ce}$ separation, with a separation factor, $\alpha$, of $\sim 30$, than for the separation of promethium from either samarium or neodymium, with a separation factor of $\sim 2$. (In general, theoretical plate heights of less than $1.5 \mathrm{~cm}$ are required for good separation.) Based on the length of overlap region that can be tolerated, the theoretical plate height, and thus the flow rate, is selected.

$247 \mathrm{Pm}$ Separation Test

To determine the behavior of the pressurized ion exchange system under intense radiation, approximately $1 \mathrm{gram}$ of ${ }^{147} \mathrm{Pm}$ was separated from $\sim 30 \mathrm{grams}$ of fission product lanthanides. Several preliminary purification steps were required prior to ion exchange because of high concentrations of iron, aluminum, and sulfate in the sample of crude fission product waste obtained from the Savannah River Plant Purex process. Both iron and aluminum sorb on the ion exchange resin with the lanthanides, which causes inefficient loading, and sulfate affects lanthanide solubility. A summary of the feed preparation steps is given in Appendix $B$. 


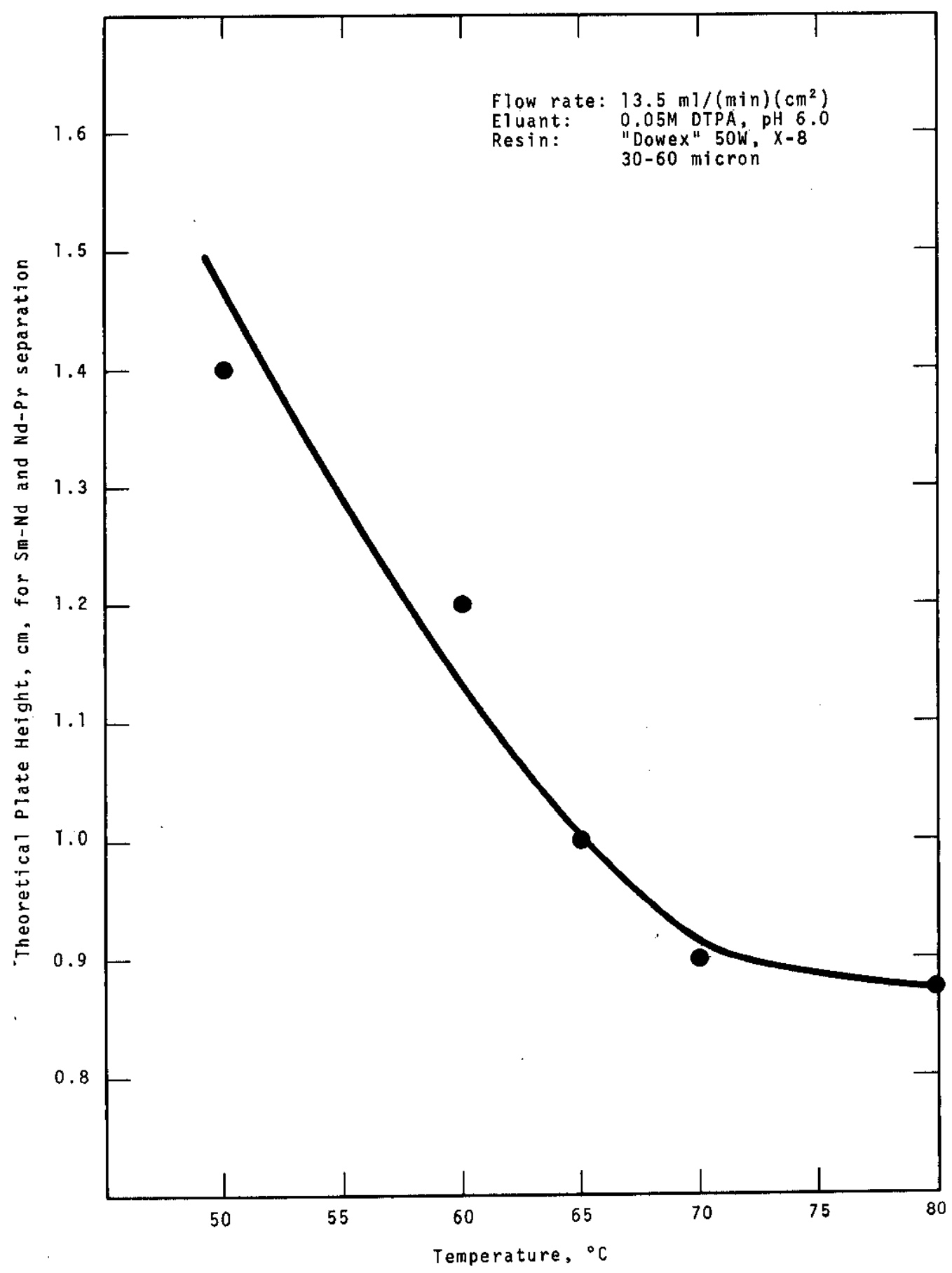

FIG. 4 VARIATION OF THEORETICAL PLATE HEIGHT WITH TEMPERATURE (DTPA) 


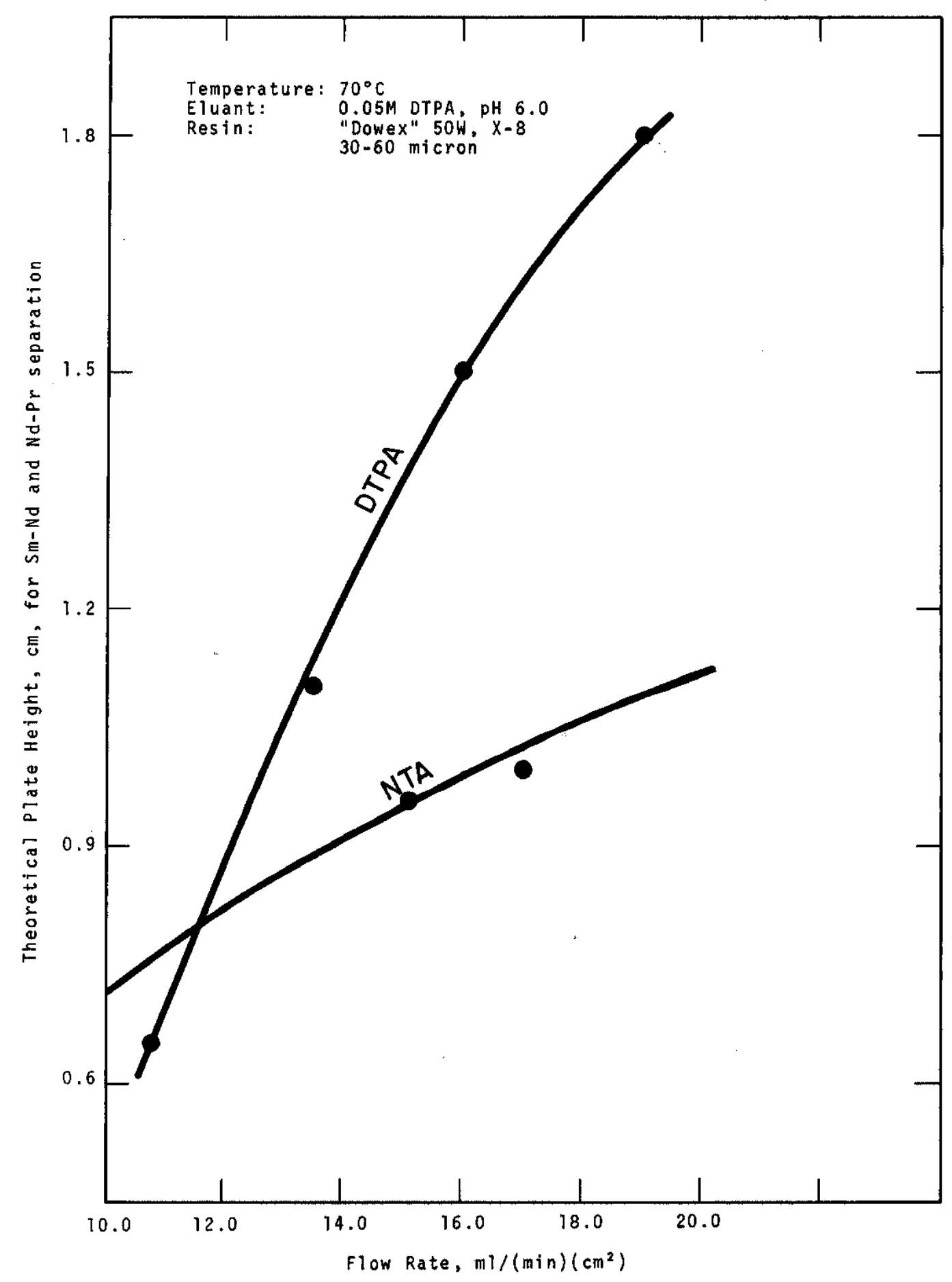

FIG. 5 VARIATION OF THEORETICAL PLATE HEIGHT WITH FLOW RATE 


\section{Equipment}

The ${ }^{147} \mathrm{Pm}$ test was performed in a four-column system, shown schematically in Figure 2, operated remotely in a shielded cell. The piping arrangement permitted independent use of each column; two streams could be pumped into the system independently. A photograph of the equipment is shown in Figure 6 . Both the water bath and the columns were located inside the cell. The columns were each 5 -feet long, with inside diameters of $1.87,0.87,0.43$, and 0.31 inches, respectively. The columns were filled with "Dowex" 50W-X8, -400 mesh $(30-60 \mu)$, cation resin. Radioactive feed was transferred by vacuum into a 3-inch-diameter feed tank, which was connected by flexible stainless steel hose to the pump outside the cell. The pump was located in an unshielded area; no radioactive solutions were pumped through it. Distilled water was pumped into the top of the feed tank, displacing the aqueous feed through a dip leg at the bottom into the column to be loaded. Although some mixing occurred, loading was $99.9 \%$ complete after three tank-volumes were pumped into the system. Even if the tank contents were continuously mixed, calculations showed that $>99 \%$ would be loaded after five tank-volumes were pumped through.

The tests with nonradioactive samarium, neodymium, and praseodymium defined the conditions used in the promethium separations test. Displacement development with $0.05 \mathrm{M}$ DTPA, adjusted to $\mathrm{pH} 6.0$ with $\mathrm{NH}_{4} \mathrm{OH}$, was started as soon as the loading was completed, since it was desirable to move the band as rapidly as possible to minimize radiolytic degradation of the resin. The columns were operated at $70^{\circ} \mathrm{C}$. The flow rate per unit area, chosen for optimum separation, was based on the smallest column in line. It was, therefore, necessary for efficient operation to delay adding the next smaller column until the band had reached the bottom of the column. The rate of band advance was known from preliminary tests to be $0.8 \mathrm{~cm} / \mathrm{min}$ at a flow rate of $15 \mathrm{~m} 1 /$ $(\min )\left(\mathrm{cm}^{2}\right)$. As the band neared the bottom of column 1 (see Figure 2), the flow rate was decreased and column 2 was added in line; the same procedure was followed in adding column 3 . As the band approached the bottom of column 3 , the effluent was collected in $500 \mathrm{ml}$ fractions. 


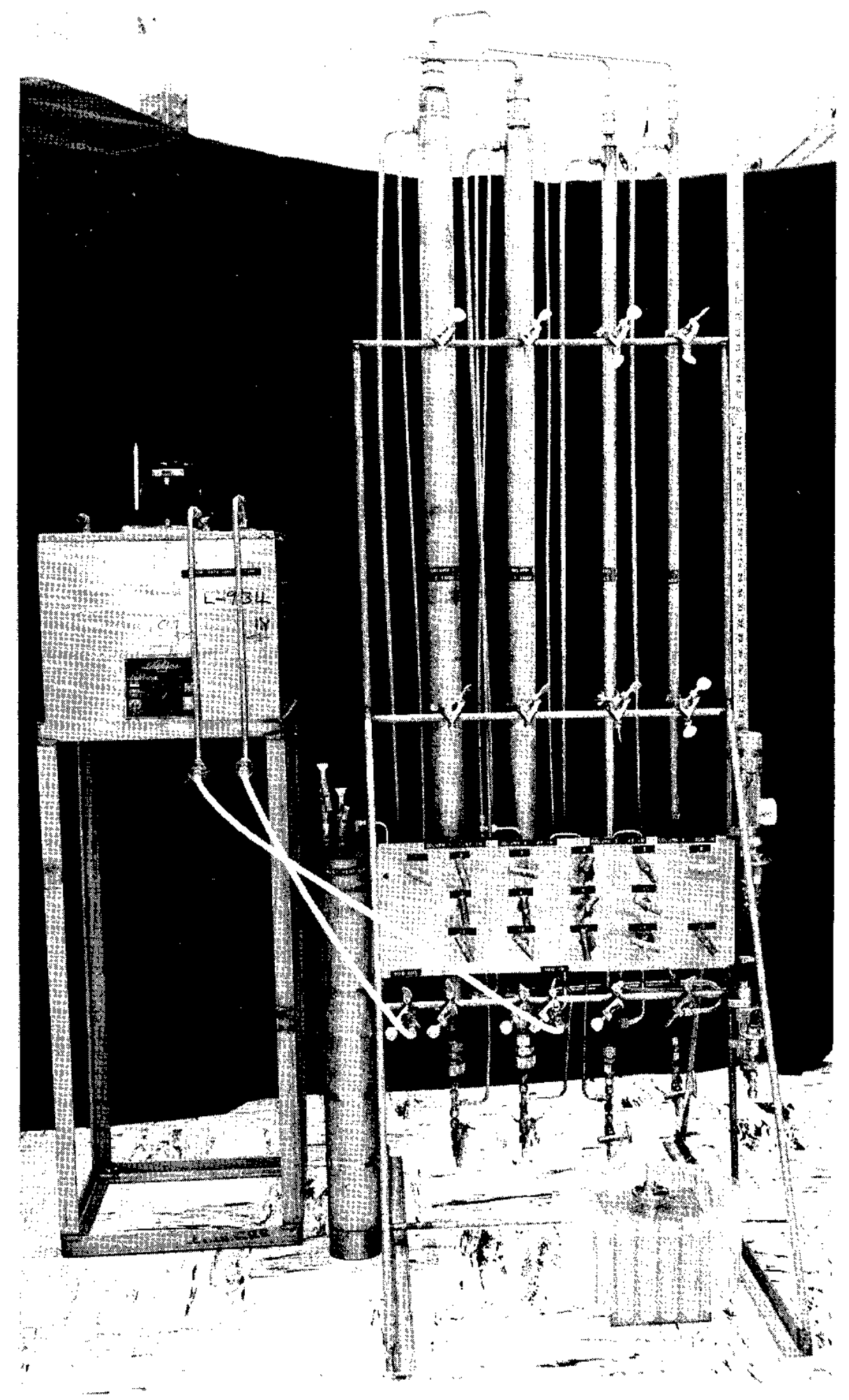

FIG. 6 PHOTOGRAPH OF FOUR-COLUMN SYSTEM 


\section{Results}

Table II shows the relative amounts of ${ }^{147} \mathrm{Pm}$ collected in the fraction containing most of the promethium and in the two fractions immediately before and after this fraction. More than $99 \%$ of the ${ }^{147} \mathrm{Pm}$ from column 3 was recovered in one fraction. Total losses from all other solutions, including ${ }^{14}{ }^{7} \mathrm{Pm}$ left in the feed tank and that in the effluent from columns 1 and 2 which was not diverted through the third column, totaled $3.1 \%$. Most of this loss was from the last effluent from column 1 before addition of column 2 .

TABLE II

Relative Amounts of ${ }^{147} \mathrm{Pm}$ in $500 \mathrm{ml}$ Eluate Fractions
$\begin{array}{cc}\text { Fraction } & \text { Relative Amounts } \\ 7 & .002 \\ 8 & .046 \\ 9 & 99.89 \\ 10 & .061 \\ 11 & .001\end{array}$

Table III shows the results of the rapid separation in terms of decontamination from major gamma-emitting fission products. Although theoretical plate heights were not determined for promethium with the adjacent lanthanides, the excellent separation from Ce-Pr and europium indicates that the performance was the same as would be predicted from the nonradioactive tests. The contamination in the product solution was determined by a 160-minute count using high-resolution gamma spectroscopy. Neither ${ }^{154} \mathrm{Eu}$ nor ${ }^{144} \mathrm{Pr}$, the most serious contaminants, was detected in the product solution. The principal impurity in the product solution was ${ }^{148} \mathrm{Pm}$. 
TABLE III

\begin{tabular}{|c|c|c|c|c|c|}
\hline \multirow[b]{2}{*}{ Isotopes } & \multicolumn{2}{|c|}{$\begin{array}{l}\text { Results of }{ }^{147} \mathrm{Pm} \\
\text { Activity, curies }\end{array}$} & \multirow{2}{*}{$\begin{array}{c}\text { Separation } \\
\text { Separation } \\
\text { Factor } \\
\end{array}$} & \multicolumn{2}{|c|}{ Concentration in Product } \\
\hline & Feed & Product & & $\mu \mathrm{g} / \mathrm{g}^{147} \mathrm{Pm}$ & $\mu \mathrm{Ci} / \mathrm{Ci}{ }^{147} \mathrm{Pm}$ \\
\hline${ }^{106} \mathrm{Rh}$ & 45 & 0.0085 & $5.2 \times 10^{3}$ & 2.5 & 17 \\
\hline $144 \mathrm{Pr}$ & 850 & $<0.0005$ & $>1.7 \times 10^{6}$ & $<0.16$ & $<0.5$ \\
\hline${ }^{95} \mathrm{Zr}$ & 1.3 & 0.0005 & $1.7 \times 10^{3}$ & 0.10 & 1.5 \\
\hline $15{ }^{4} \mathrm{Eu}$ & 3.2 & $<0.0005$ & $>6.4 \times 10^{3}$ & $<3.5$ & $<0.5$ \\
\hline
\end{tabular}

Results of the high speed cation exchange demonstration indicate that this technique can be successfully applied to processing of highly radioactive solutions, thereby decreasing resin degradation and processing times. In addition, either a higher capacity can be achieved or a smaller system can be used than in a comparable system using larger particle cation exchange resins.

\section{ACKNOWLEDGMENT}

The participation of D. F. Hallman, F. D. R. King, and A. S. Jennings in the safety analysis of the high pressure ion exchange system used to isolate the ${ }^{147} \mathrm{Pm}$ is greatly appreciated. 
APPENDIX A

Calculation of Minimum Movement Distance and Length of Binary Zone

For the separation of ${ }^{147} \mathrm{Pm}$ from a mixture of fission product lanthanides, the following data apply for the calculations utilizing Equations 3 and 4.

$$
\alpha_{\mathrm{Pm}}^{\mathrm{Nd}} \approx \alpha_{\mathrm{Sm}}^{\mathrm{Pm}}=2.3
$$

The lanthanides elute in inverse order of atomic number. Samarium is produced in significant fission yield and is eluted just before ${ }^{147} \mathrm{Pm}$. In this case, $\mathrm{N}_{0} \approx 0.95$. Therefore the minimum number of band lengths, $\gamma$, which the band must be displaced to establish the steady state overlap region is

$$
\gamma=\frac{1+\left(\alpha_{\mathrm{Sm}}^{\mathrm{Pm}}-1\right) \mathrm{N}_{\mathrm{o}}}{\left(\alpha_{\mathrm{Sm}}^{\mathrm{Pm}}-1\right)}=\frac{1+(1.3)(0.95)}{1.3}=1.7
$$

The length of the overlap region can be calculated from Equation 4. For example, the length of resin column that would contain a concentration ratio of $\mathrm{Sm}: \mathrm{Pm}$ of $10^{4}$ i.e., $\mathrm{Sm} / \mathrm{Pm}=100$ to $\mathrm{Sm} / \mathrm{Pm}=0.01$ is $12.2 \mathrm{~cm}$ assuming a theoretical plate height of $1.0 \mathrm{~cm}$.

$$
\begin{aligned}
& \log \left(\frac{100}{0.01}\right)=\frac{L}{1.0} \log (2.3) \\
& L=\frac{(1.0)(4.0)}{0.362}=12.2 \mathrm{~cm}
\end{aligned}
$$




\section{APPENDIX B \\ Feed Preparation for $147 \mathrm{Pm}$ Separation Test}

Feed preparation steps for the rapid ion exchange separation of promethium included:

- Separation from aluminum, iron, and sulfate by batch extraction of the lanthanides with $50 \%$ TBP.

- Removal of ${ }^{144} \mathrm{Ce}$ by electron exchange with inactive $\mathrm{Ce}(\mathrm{IV})$, and extraction of Ce(IV) with $50 \%$ TBP.

- Removal of ammonium and hydrogen ions by sodium hydroxide precipitation of Ianthanide hydroxides.

In preparation for the first batch extraction step, $\mathrm{Al}\left(\mathrm{NO}_{3}\right)_{3}$ solution was added as a salting agent, and the feed solution was evaporated to its original volume. The feed was adjusted to the composition shown in Table B-I; lanthanides were batch extracted with an equal volume of $50 \% \mathrm{TBP}$, and back-extracted into two halfvolumes of $0.1 \mathrm{M} \mathrm{HNO}_{3}$. The analyses of the back-extracted solution after a fourfold evaporation are also shown in Table B-I.

The data in Table B-I show that aluminum, iron, and sulfate were removed by factors of $>800,>80$, and 72 , respectively. Both aluminum and iron concentrations in the product solution, after fourfold evaporation, were less than 0.01M. Decontamination factors for gamma emitters, ${ }^{95} \mathrm{Zr}$ and ${ }^{106} \mathrm{Rh}$, were ${ }^{10}$ and ${ }^{2} 13$ respectively; these values are probably not accurate to more than $\pm 50 \%$ because $299 \%$ of the activity was from ${ }^{144} \mathrm{Ce}-144 \mathrm{Pr}$. 
TABLE B - I

Batch Extraction Results

\begin{tabular}{|c|c|c|c|}
\hline Component & Feed $^{(a)}$ & Raffinate ${ }^{(a)}$ & $\begin{array}{l}\text { Product after } \\
\text { Evaporation } \\
\end{array}$ \\
\hline $\mathrm{H}^{+}, \mathrm{M}$ & 1.68 & 0.31 & 3.82 \\
\hline $\mathrm{Al}^{3+}, \mathrm{M}$ & 2.07 & 1.89 & $<0.01$ \\
\hline $\mathrm{Fe}^{3+}, \mathrm{M}$ & 0.20 & 0.16 & $<0.01$ \\
\hline $\mathrm{NO}_{3}{ }^{-}, \mathrm{M}$ & 8.67 & - & - \\
\hline $\mathrm{SO}_{4}^{2-}, \mathrm{M}$ & 0.45 & 0.19 & 0.027 \\
\hline${ }^{147} \mathrm{Pm}, \mathrm{Ci} / \ell$ & 230 & 0.23 & 640 \\
\hline $14^{44} \mathrm{Pr}, \mathrm{Ci} / \ell$ & 590 & 120 & 1300 \\
\hline${ }^{95} \mathrm{Zr}, \mathrm{Ci} / \ell$ & 1 & 0.010 & $\sim 20^{(c)}$ \\
\hline${ }^{106} \mathrm{Ru}, \mathrm{Ci} / \ell$ & 105 & 14 & $\sim 16^{(c)}$ \\
\hline $15^{4} \mathrm{Eu}, \mathrm{Ci} / \ell$ & 0.07 & 0.005 & $\sim 0.14^{(c)}$ \\
\hline
\end{tabular}

(a) Volume of feed, raffinate, and product solutions were 8 liters.

(b) Volume of product solution after evaporation was 2 liters.

(c) Values are not accurate to more than $\pm 50 \%$ because of predomiance of ${ }^{144} \mathrm{Ce}-1{ }^{14} \mathrm{Pr}$.

Analyses for ${ }^{147} \mathrm{Pm}$ indicated that $<0.1 \%$ was 10 st in the raffinate; the raffinate analysis was probably low, however, because $\sim 20 \%$ of the ${ }^{144} \mathrm{Pr}$ and $\sim 10 \%$ of the ${ }^{154}$ Eu were not extracted, and extraction should be about equal for all of the lanthanides. The product solution contained 1.4 grams of ${ }^{147} \mathrm{pm}$, which also indicates a loss of $\sim 20 \%$ in the batch extraction.

In the next feed preparation step, ${ }^{144} \mathrm{Ce}$ was rejected by adding nonradioactive $\mathrm{Ce}(\mathrm{IV})$ as $\left(\mathrm{NH}_{4}\right)_{2} \mathrm{Ce}\left(\mathrm{NO}_{3}\right)_{6}$, which undergoes electron exchange with fission product ${ }^{144} \mathrm{Ce}($ III). The Ce(IV) was extracted from the trivalent lanthanides in $3.8 \mathrm{M} \mathrm{HNO}_{3}$ by batch extraction with $50 \%$ TBP. The fraction of cerium removed depends on the ratio of $\mathrm{Ce}(\mathrm{IV})$ added to total fission product $\mathrm{Ce}$ (III) in the feed, and on the amount of Ce(IV) reduced by impurities in the solution or by radiolysis. The ratio of $\mathrm{Ce}$ (IV) added to fission product Ce(III) was 7 , corresponding to a theoretical rejection of $87 \%$. A miniature centrifugal decanter was used for rapid phase 
separation, after the organic and aqueous were mixed for 10 minutes to permit equilibrium in the exchange reaction. Seventy percent of the ${ }^{144} \mathrm{Ce}$ was extracted, accompanied by only $3 \%$ of the $1{ }^{4} \mathrm{Pm}$. The difference between the theoretical and observed $1{ }^{44} \mathrm{Ce}$ removal was probably due to reduction of $\mathrm{Ce}(\mathrm{IV})$ by radiolytically generated reductants, such as nitrite.

The final step in the feed preparation for cation exchange was precipitation of the lanthanide hydroxides, to remove the monovalent $\mathrm{NH}_{4}{ }^{+}\left(0.4 \mathrm{M}\right.$ from $\mathrm{Ce}(\mathrm{IV})$ addition) and $\mathrm{H}^{+}$(3.5M) cations from the feed solution. Earlier tests showed that $1 \mathrm{M}$ monovalent cations can be tolerated in a feed mixture containing $0.1 \mathrm{M}$ 1 anthanides, but at higher concentrations the monovalent ions cause inefficient lanthanide loading of the column.

The lanthanides were precipitated by addition of the ${ }^{147} \mathrm{Pm}$ solution to $6 \mathrm{M} \mathrm{NaOH}$. After vacuum filtration and washing, the solids were dissolved with a small excess of concentrated $\mathrm{HNO}_{3}$, and diluted to 2 liters for feed to the ion exchange columns. 


\section{APPENDIX C \\ Safety Analysis of Four-Column System}

The four ion-exchange columns were arranged so that the columns could be operated either in series or individually. A positive-displacement pump delivered pressurized feed solution to the system at approximately two milliliters per stroke at a rate of about 48 strokes per minute. The columns could be fed either directly from the pump or through a 3-1iter feed tank. Two 6-inch pressure gauges with a $0-1500 \mathrm{psi}$ range were used to measure system pressures; one gauge measured pressure of solution fed directly from the pump, while the other measured the pressure of the solution fed through the feed tank. Each feed line passed through a relief valve set to open at $1000 \mathrm{psi}$. The solution was transferred between columns through $1 / 4$-inchOD by $1 / 8$-inch-ID stainless steel tubing. "Swagelok"* fittings and Hoke Incorporated valves are used in the system. A highpressure, flexible stainless steel, hose was used in the system. Water jackets were welded around the columns to provide for temperature control; water of a specified temperature was supplied by a constant-temperature water bath.

A schematic diagram of the system is shown in Figure 2; Table C-I gives allowable working pressures for the system components. Prior to startup, the 2-inch-diameter ion exchange column was pressure tested to 1000 psig; no leaks were detected.

*Trademark of Crawford Fitting Co. 


\section{Table C-I}

Allowable Working Pressures for System Components

\begin{tabular}{|c|c|c|c|}
\hline Component & $\begin{array}{c}\text { Outside } \\
\text { Diameter, } \\
\text { In. } \\
\end{array}$ & $\begin{array}{c}\text { Wa11 } \\
\text { Thickness, } \\
\text { In. } \\
\end{array}$ & $\begin{array}{c}\text { A11owable Working } \\
\text { Pressure, } \\
\text { psi }\end{array}$ \\
\hline Column 1 & 2.0 & 0.065 & $1155^{(a)}$ \\
\hline Column 2 & 1.0 & 0.065 & $2420^{(a)}$ \\
\hline Column 3 & 0.5 & 0.035 & $2780^{(a)}$ \\
\hline Column 4 & 0.375 & 0.035 & $3780^{(\mathrm{a})}$ \\
\hline Feed Tank & 3.50 & 0.216 & $2430^{(a)}$ \\
\hline Tubing & 0.25 & 0.0625 & 6000 \\
\hline Valves $\left(1 / 4^{\prime \prime}\right)$ & & & 3000 \\
\hline SS Hose & & & 3280 \\
\hline
\end{tabular}

(a) These working pressures were calculated using design equations and stress values from the ASME Unfired Pressure Vessel Code.

The system undergoes a pulsating pressure because a positive-displacement pump is used. The period of the pulses ( $\simeq$ one second) is such that no additive pressure wave effects are set up in the system. This system was operated at maximum pressures less than 800 psi, with a pressure fluctuation of less than $250 \mathrm{psi}$, for an operating time of less than 100 hours. Under these conditions metal fatigue in 316 stainless steel is not a significant problem.

Nitrate solutions cause negligible corrosion of 316 stainless steel. The corrosion rate of 316 stainless steel in DTPA was found to be less than one mil/year. Spotchecks of column effluent in preliminary runs showed no measurable amount of iron in solution. 


\section{REFERENCES}

1. "Use of Isotopic Power to Drive an Artificially Implanted Human Heart," Nucleonics Week 6, (23) 5 (1965).

2. D. F. Peppard, G. W. Mason, W. J. Drisco11, and R. J. Sironen, "Acidic Esters of Orthophosphoric Acid as Selective Estractants for Metallic Cations - Tracer Studies," J. Inorg. Nucl. Chem. 7, 276-82 (1958).

3. P. B. Orr, Ion Exchange Purification of Promethium-147 and Its Separation from Americium-241, with Diethylene triaminepentaacetic Acid as the Eluant, USAEC Report ORNL3271, Union Carbide Corp., Oak Ridge National Laboratory, Oak Ridge, Tenn. (1962).

4. E. J. Whee1wright et al., Ion-Exchange Separation of Kilocurie Quantities of High Purity Promethium, USAEC Report BNWL-318, Batte11e Memorial Institute, Pacific Northwest Laboratory, Richland, Wash. (1966).

5. E. J. Wheelwright and $T$. R. Meyers, Investigation of NTA as a Replacement for DTPA in the Ion Exchange Purification of Promethium, USAEC Report BNWL-SA-1493, Battelle Memoria1 Institute, Pacific Northwest Laboratory, Richland, Wash. (1968).

6. S. R. Buxton and D. 0. Campbe11, Application of High Pressure Ion Exchange column to the Separation of Trivalent Actinides and Lanthanides, USAEC Report ORNL-TM-1876, Union Carbide Corp., Oak Ridge National Laboratory, Oak Ridge, Tenn. (1967).

7. F. Helfferich, Ion Exchange, Chapter 9, McGraw-Hill Book Co., New York (1962).

8. F. H. Spedding and A. H. Daane (editors), The Rare Earths, Chapter 5, John Wiley and Sons, Inc., New York (1961).

9. E. J. Wheelwright and T. R. Meyers, Parametric Evaluation of DTPA, EDTA, and HEDTA for Ion Exchange Purification of Promethium, USAEC Report BNWL-69, Battelle Memorial Institute, Pacific Northwest Laboratory, Richland, Wash., (1965).

10. D. C. Stewart and D. Cato, "Analysis of Rare Earth Mixtures by a Recording Spectrophotometer," Anal. Chem. 30, (2) 164-72 $(1958)$. 